Article

\title{
Promoting Social Media Engagement Via Branded Content Communication: A Fashion Brands Study on Instagram
}

\author{
Bárbara Castillo-Abdul ${ }^{1,2}$, Ana Pérez-Escoda ${ }^{3, *}$, and Estela Núñez-Barriopedro ${ }^{4}$ \\ ${ }^{1}$ Department of Communication Sciences and Sociology, Rey Juan Carlos University, Spain \\ 2 ESAI Business School, Espiritu Santo University, Ecuador \\ ${ }^{3}$ Department of Communication, University Antonio de Nebrija, Spain \\ ${ }^{4}$ Department of Economics and Business Management, University of Alcalá, Spain \\ * Corresponding author (aperezes@nebrija.es)
}

Submitted: 22 July 2021 | Accepted: 16 September 2021 | Published: 24 February 2022

\begin{abstract}
Social networks have become crucial communication channels for brands through awareness, engagement, and word of mouth. Instagram is firmly positioned as a direct gateway between brands and consumers, as it became the fifth most-used social network globally in 2021. As such, branded content is expected to increase the brand's likability, by capturing the interest and attention of the consumer, which could differ depending on what social media platform is used. This study aims to analyze whether there is a relationship between the branded content published on the Instagram profile of luxury brands (Manolo Blahnik and Loewe) and the interactions of and with its followers, focusing on branded content communication associated to industrial, social responsibility, and commercial issues. A correlational study is presented using a quantitative methodology to test the hypotheses through an ANOVA analysis. The results show which type of content is more productive on Instagram's social network profile, helping diffusion of the firm, as it provokes more reactions from followers when using branded content related to social responsibility. It is also worth noting the extent of the interactions that branded content shows within the brand, whose influence is detected not in averages but in reach. The study's conclusions allow us to affirm that branded content directly impacts brand reputation, generating positive engagement in all the cases analyzed. The study contributes to a better understanding of the branded content effect on consumers.
\end{abstract}

\section{Keywords}

branded content; digital communication; engagement; Instagram; luxury; social media

\section{Issue}

This article is part of the issue "New Narratives for New Consumers: Influencers and the Millennial and Centennial Generations" edited by Luis M. Romero-Rodríguez (Rey Juan Carlos University), Santiago Tejedor (Autonomous University of Barcelona), and Inmaculada Berlanga (International University of La Rioja).

(C) 2022 by the author(s); licensee Cogitatio (Lisbon, Portugal). This article is licensed under a Creative Commons Attribution 4.0 International License (CC BY).

\section{Introduction}

Consumption, interaction, and communication mediated by social media and mobile apps (Pérez-Escoda et al., 2016) have undergone a considerable transformation in all their processes, giving rise to new narratives for an audience that is continuously connected through mobile devices, mainly fostered by digital platforms (Pérez-Tornero \& Pedrero-Esteban, 2020). The mediation of the internet has extensively modified relationships between brands and customers. Social networks have transformed consumers' role, emerging like active users where brands interact directly with them (Castillo-Abdul, Pérez-Escoda, \& Civila, 2021). Branded content as a network marketing technique is firmly positioning itself in the online environment not only as an effective strategy for the creation of content related to brands (Chen \& Shupei, 2019), but also as an effective narrative tool 
in the fight against the recent phenomenon known as infodemic, which emerged and was fostered during the Covid-19 pandemic situation with fake news (Pérez-Escoda et al., 2021).

One of the most crucial issues that arises within this framework is the engagement produced by the branded content, which reaches users during this interaction. As described by Voorveld et al. (2018), "social media engagement is defined as the emotional, intuitive experiences or perceptions that people undergo when using a particular medium at a particular moment" and we can also add, when interacting with a particular brand. As previously indicated by Voorveld (2019), this situation establishes theoretical and practical implications for research in this field. Theoretical implications relate to the ongoing evolution of communicative processes involving new strategies and phenomena, such as engagement (Sádaba \& Pérez-Escoda, 2020). Practical implications change relationships between brands and customers, who can now communicate with each other in a direct and bidirectional manner.

In this regard, this article asks if a relationship exists between the brand content published on the Instagram accounts of two luxury brands in the textile sector, and the interactions with their followers. Specifically, we analyze the extent to which brand content influences the luxury retailers Manolo Blahnik and Loewe's Instagram audience and their interactions on the network as social media consumers of these fashion brands. This study allows us to determine what type of content is more productive on the Instagram social network, by helping with the diffusion of the firm, as it provokes more reactions among the followers.

\section{Theoretical Framework}

\subsection{Branded Content as Digital Narrative for Engagement}

Digital narratives can be described as a set of communication techniques arranged in a digital context that can be designed with different purposes, depending on who designs them and what is designed for them. The increasing use of social media in advertising and marketing has positioned branded content as a beneficial strategy promoting and positioning brands and activating interaction processes with clients (Castillo-Abdul et al., 2020). It is worth mentioning that the conceptualization of branded content has integrated different scopes. On the one hand, some authors have highlighted the communicative perspective, considering branded content as an emergent form of marketing communication media (Sánchez-Cobarro et al., 2021). On the other hand, we found creative perspectives in which content was understood explicitly as a tool for consumers' entertainment (Ashley \& Tuten, 2015). Aside from the perspective taken, according to Bezbaruah and Trivedi, branded content can be differentiated from advertising in terms of its objectives. While the objective of advertising is to sell the product, the objective of branded content is to provide consumers with valuable information to achieve other goals, being considered "more of a pull strategy than a push one" (2020, p. 2).

According to this point of view, branded content generates engagement with users/clients, thereby establishing an interaction-based relationship, as shown in previous literature (Dessart, 2017). In this study, we use a three-part approach to the concept, by firstly including the communicative perspective, secondly the entertainment one, and thirdly the interactive one related to engagement. Regarding this perspective, Castillo-Abdul et al. (2020) have previously defined branded content as a topic of interest within the area of marketing and commerce, because brands must make themselves known, must promote continuously, update their content in order to be recognized and attain better positioning and, above all, maintain that content through different distribution channels, to generate value for customers and followers.

Engagement has been defined as a multi-dimensional phenomenon with different stages of commitment, but generally starting from a psychological state of motivation that results from the act of following (Barger \& Labrecque, 2013). The degree of commitment is shown in different ways, gaining a greater importance since social media became a relevant scenario for brands to establish new relationships with their clients. As previously highlighted by Voorveld et al. (2018), defining engagement is a challenging task, considering the different experiences found in digital platforms. Therefore, this research will focus on the user consumption of shared content through their active participation in commenting. Thus, our conceptualization of the term is in line with Bentley et al. (2021), in which engagement is considered as intense behaviour or media use (likes, shares, and comments), to create, generate online wordof-mouth, and communicate with brands and other consumers and not as a predictive issue for consumption (Calder et al., 2016).

\subsection{Fashion Brands and Social Media}

The opportunities provided by social media for companies and brands to communicate with users and potential clients has increased the use of social media and the creation of branded content as an essential tool in the digital communication process, promoting an extensive transformation in the way brand content is created, distributed, and released (Núñez-Barriopedro et al., 2013; Wahid \& Gunarto, 2021). Moreover, communication processes have been enhanced by the direct dialogue offered by social media among brands and clients, becoming two-way and real-time interactions favored by the penetration of networks among all the populations that use them intensively, and promoting different experiences such as happiness (Castillo-Abdul, Pérez-Escoda, 
\& Civila, 2021; Cuesta-Valiño et al., 2021), positive feelings (Casaló et al., 2020), or sharing attitudes (Choi \& Lee, 2019). In this sense, social media emerges as a more suitable scenario for maintaining continuous and ubiquitous communication, establishing an in-depth relationship with audiences that demand increasing amounts of information from brands (Castillo-Abdul, Bonilla-del-Río, \& Núñez-Barriopedro, 2021). In the current situation of the global pandemic lockdown, in which peer-to-peer interaction was globally and massively canceled, Instagram has become one of the most engaging social networks. According to Kemp (2021) Digital 2021: Global Overview report, Instagram was the third most important social media in average time spent, with 10.3 hours per month, and the fifth most used platform globally, only surpassed by Facebook, YouTube, WhatsApp, and FB Messenger. Focusing on the fashion industry, Instagram is considered one of the most critical and influential branded content promotion strategies (Jin \& Ryu, 2020; Sánchez-Cobarro et al., 2021).

The fashion sector has changed in a profitable way with audiences since the projection, distribution, positioning, and consumption processes were highly transformed due to the online environment. These undeniable changes have given way to innovative fashion marketing strategies, in which consumers and users stopped being passive and have become prosumers, consuming, and generating content in a very playful way as stated by Belanche et al. (2021). As highlighted by Kong et al. (2021), luxury fashion brands have been the main contributors to the slow but steady growth rate within the global luxury market, with an estimated value of 1,015 billion euros by 2021 and 465 million consumers. In this respect, the fashion luxury industry plays a relevant role in the transformation of marketing and advertising mediated by social media. The branded content strategies associated with engagement, and promoted among audiences by luxury brands, seem to be mainly of interest in the field of new communication narratives, crucial for understanding present-day marketing (Pérez-Curiel \& Sanz-Marcos, 2019).

\section{Objectives and Hypothesis}

The main objective of this work is to explore if there is a relationship between the brand content published on the Instagram accounts of two luxury brands in the textile sector and the interactions of their followers. Specifically, we analyze the extent to which brand content influences the luxury retailers Manolo Blahnik and Loewe's Instagram audience and their interactions on the network as social media consumers of this fashion brand. This study allows us to determine what type of content is the most productive on the Instagram social network, helping to promote the brand as it provokes more reactions from followers. With this objective in mind, the following hypotheses were posited:
$H 1$ : Brand content influences the follower's feelings towards the brand.

The effect of brand content on social media, specifically in its interaction through digital platforms, is not limited to being just another means of promotion by creating a "new paradigm" in the fashion sector, but it is committed to boosting the marketing of fashion, actively including the customer, their experience with the brand, creative advertising, and new business opportunities (Kim \& Kim, 2020). In this way, brands and consumers have become active social actors in the networks, because, in addition to becoming prescribers of the brand and generating trust among their peers by reacting with likes to certain publications of brand content, they seek to expand their network of contacts and thus manage to effectively extend the dissemination of the message (Capriotti, 2013):

\section{$\mathrm{H} 2$ : Brand content influences positive feedback.}

Previous research (Casaló et al., 2017) argues that perceived originality is the most relevant content feature for developing perceived hedonism. Perceived hedonism, in turn, affects the intention to interact, and the actual interaction on a brand's Instagram account as well. Thus, hedonism creates interaction in networks (Correia-Loureiro et al., 2018). In this line of research, one of the original contributions of the present work was to discover if the type of brand content published on the Instagram account of a luxury fashion brand has a positive influence on the generation of positive comments or positive feedback on the brand and/or products it markets:

\section{H3: Brand content influences neutral commentary.}

The fashion industry has developed its own manner of communication in digital media, which is a key instrument for promoting its commercialization. Therefore, social networks offer the possibility for companies to communicate with their current and potential customers publicly, which in turn allows them to carry out market research (Wu et al., 2020) and to collect comments from them, which, despite being neutral, can serve as a source of information. Therefore, another original contribution of the present work is to discover what type of brand content generates more neutral comments and contributes as a source of information:

\section{H4: Brand content influences negative comments.}

Digital marketing has become an essential tool for promoting luxury brands to younger audiences, as stated by González-Romo and Plaza-Romero (2015). Therefore, the evaluation of social network users' emotional response, whether positive, neutral, or negative, to a firm's brand content has become a fundamental task in the design 
of products for the fashion industry. Thus, this work increases knowledge on what kind of brand content influences each of the user's comments in the network, even the negative ones. From a practical point of view, this information can be exploited to reformulate the digital communication strategies of brands (Bonilla et al., 2019).

\section{Method}

An exploratory quantitative study was carried out with an in-depth review of the most relevant literature, followed by a correlational study to test the hypotheses, using an ANOVA analysis with the SPSS version 27.

In digital communication, an ANOVA analysis is appropriate (Hair et al., 2010), as it allows the analysis of behaviors in response to different stimuli (Castañeda et al., 2020; Pinto \& Yagnik, 2017). Specifically, the influence of each category of the independent variable (branded content) on the dependent variable (consumer interactions) was analyzed. It is particularly suitable for research which seeks to analyze behavior in a digital information context. In this way, the effect of each of the categories from the independent categorical variable "brand content," on the dependent variable "consumer interactions" was analyzed. In this way, the ANOVA analysis allows us to examine the variance within a data set to determine the existence of significant differences between the mean values of a dependent variable (Hair et al., 2010).

The independent variable considered was brand content, categorized into industrial, corporate social responsibility, commercial, and influencers. On the other hand, the explanatory or dependent variable would be the interactions of the social media consumers on Instagram. The following variables were considered here: sentiments towards the brand (likes) and comments (negative, neutral, and positive).

Based on the literature review, a mapping of theoretical and categorical variables was carried out to analyze content and discourse on the Instagram social network, as well as to identify dimensions and performance indicators (KPIs), interactions, and engagement. For this screening, all the emerging categories of analysis in the different documents were used, integrating those that analyzed the same objects with the same or different names (homologation procedure) into integrated dimensions.

This instrument was configured by independent variables (date, time, day of the week), co-variables (type of post, type of image, colors, message...), and dependent variables (reactions, comments, likes...), as can be observed in Table 1, which made it possible to posteriorly

Table 1. Definition of the study's variables, dimensions, and indicators.

\begin{tabular}{|c|c|c|c|}
\hline Type of variable & Dimension & Indicators & Type of analysis \\
\hline \multirow{16}{*}{ Independent } & Date & Date & \multirow{8}{*}{ Quantitative } \\
\hline & Day of the week & $M=1 ; T=2 ; W=3 ; T h=4 ; F=5 ; S=6 ; S u=7$ & \\
\hline & Time of publication & Time of publication (Spain) & \\
\hline & \multirow{5}{*}{ Type of post } & Text and photo (TP) & \\
\hline & & Text and video (TV) & \\
\hline & & Photo only (P) & \\
\hline & & Photo reel (MP) & \\
\hline & & Video only (V) & \\
\hline & Text & Textual and discourse analysis through QDA & Qualitative \\
\hline & \multirow{4}{*}{ Post content type } & Commercial (C) & \multirow{6}{*}{ Quantitative } \\
\hline & & Personal (P) & \\
\hline & & Industrial and manufacturing (I) & \\
\hline & & Corporate Social Responsibility (RSC) & \\
\hline & \multirow{2}{*}{ Chromatics of the image(s) } & Monochromatic (BW) & \\
\hline & & Chromatic (FC) & \\
\hline & Image(s) & Analysis of photographic or audiovisual content & Qualitative \\
\hline \multirow{4}{*}{ Dependent } & & Positive (FPC) & \multirow{4}{*}{$\begin{array}{l}\text { Quantitative, through } \\
\text { lexical categorization }\end{array}$} \\
\hline & Dependent & Neutral (FOC) & \\
\hline & & Negative (FNC) & \\
\hline & Reactions & Likes (IL) & \\
\hline
\end{tabular}


contrast different types of variables to obtain correlations with different measurement scales.

Some of these structured dimensions allow for dichotomous or polytomous coding, while others will be possible using interpretive content analysis and textual discourse analysis with lexicon cataloging. Specifically, adjectives or emoticons were used to identify and categorize emerging feelings (positive, negative, and neutral).

Once the theoretical instrument was constructed, a round of expert judgment was carried out to determine its reliability, construct, and content validity, to be able to determine variables that were considered dispensable and others that may emerge from the different observations of the panel's specialists. As for the overall assessment of the instrument, a score of over $3(V G=\geq 3$ ) was obtained as a unit of measurement that reports the averages provided by each judge to the taxonomy as a whole, thereby providing its internal consistency.

The data was obtained and collected from the messages published on the Instagram social network about the luxury fashion brand Manolo Blahnik and the luxury brand Loewe in one quarter, more specifically in March, April, and May 2020. Therefore, a three-month sample has been selected using a convenience sampling system (Otzen \& Manterola, 2017). This period was selected to coincide with the first wave of the Covid-19 pandemic, as the first lockdown took place during this period, and it could contribute to a better understanding of consumer behavior on the network. Likewise, each of the follower interactions provoked by each message disseminated by the brand was measured.

\subsection{Sample}

One of the novelties of this research is that the luxury brands Manolo Blahnik and Loewe were chosen due to their high brand awareness as leading international luxury fashion brands. The brands under study are Spanish, either because they were born in Spain, as in the case of Loewe, or because they were created abroad by a designer of Spanish origin, such as Manolo Blahnik.

Loewe has been in the market for more than 100 years, while Manolo Blahnik has been in the market for 48 years, all with a presence in the Spanish domestic market and with a presence in more than 40 countries around the world. In addition, the selection criteria for these luxury fashion brands were based on their participation in the haute couture of the most essential fashion catwalks in the world and for being brands that have received recognition, not only from the international market, but also from the top critics in the industry.

The brands in question have received awards and prizes both in Spain and the rest of the world. There has been so much exposure of the brands origin country, Spain, that it has been part of the top film industry in Hollywood through these fashion brands. Along this lines, Loewe and Manolo Blahnik are emblematic brands that refer to Spanish art and culture in their designs.
Additionally, Manolo Blahnik currently has more than 300 shops worldwide, in addition to 20 flagship stores in key locations such as Madrid, New York, Hong Kong, and Geneva (Castillo-Abdul, Bonilla-del-Río, \& NúñezBarriopedro, 2021). It is also one of the luxury brands chosen by the film industry, for example, in the series Sex and the City, where it is shown as successful branded entertainment (Bug \& Blau, 2020). In addition, it is recommended by the most popular influencers and celebrities. On its part, the firm Loewe is considered an international luxury brand that belongs to a leading holding company in the field of fashion. Loewe exports more than $75 \%$ of its production and has around 150 points of sale in 32 countries, including its shops and franchises. Its flagship shops are located in Madrid, Beijing, Tokyo, London, and Singapore (Cantista \& Sádaba, 2020). On social networks, Manolo Blahnik has more than 328,000 followers on Facebook and more than 3,325,000 followers on Instagram. Likewise, Loewe has 669,823 followers on Facebook and 2,9 million followers on Instagram. Instagram is therefore the most convenient social network for our study because it has, among brands, a larger number of followers as current or potential consumers.

\section{Results}

In each of the following sub-sections, the hypotheses proposed in the model shown in Figure 1 are tested.

A standard behavior among the followers of Manolo Blahnik and Loewe brands is to share the feelings of liking, which can be generated by each of the publications on Instagram. Therefore, we return to the hypotheses drawn in Section 3:

H1: Brand content influences the follower's feelings towards the brand.

Table 2 shows that followers of the Manolo Blahnik brand react with an average of 21632.4 likes to industrial publications, with an average of 22955.9 likes found in social responsibility publications, 26229.94 likes on average for commercial publications, and 24542 likes on average for influencer publications.

Meanwhile, followers of the Loewe brand react to industrial publications with an average of 27539.85 likes, with an average of 14652.58 likes to social responsibility publications, with 6276.6 likes on average to commercial publications, and with 116385.56 likes on average to influencer publications. Likewise, for all categories of brand content, the standard deviation was very high, which is usual when studying behaviors in social networks, since the type of sentiment materialized as likes by followers is very diverse.

Table 3 shows that according to the $F$ statistic of the ANOVA analysis for $95 \%$ confidence, the differences between the average likes of followers of the Manolo Blahnik brand and the different categories of brand content are not significant, with an $F$ of 0.10 and a 


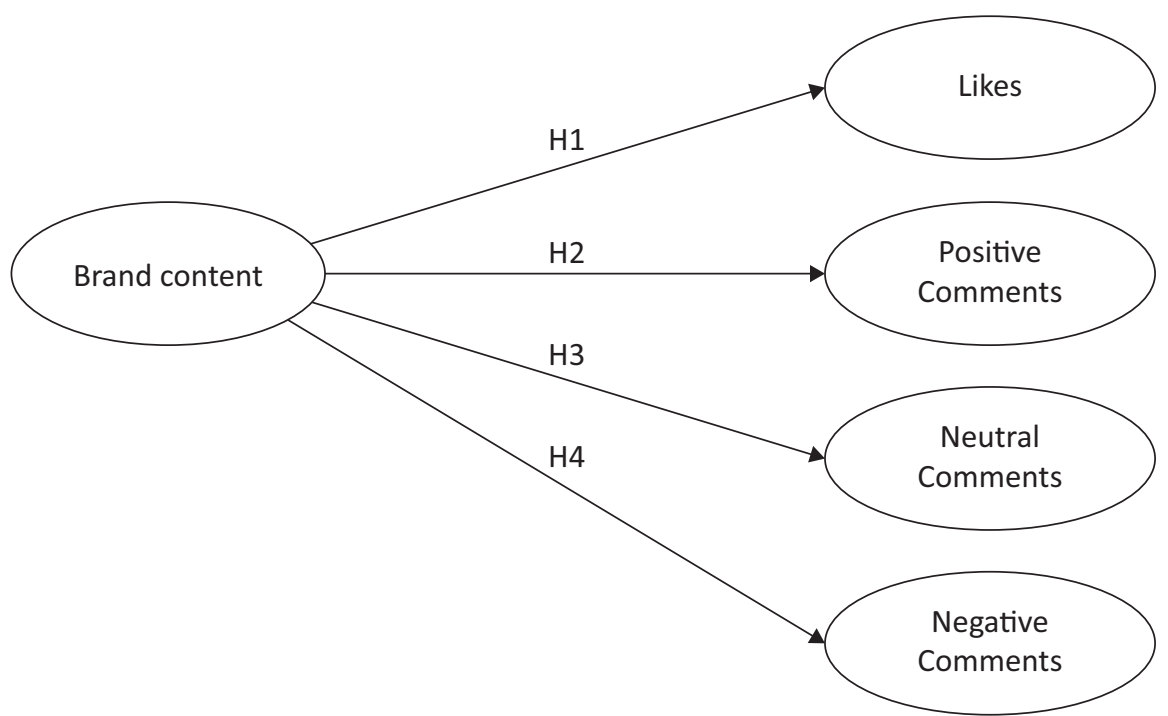

Figure 1. Model showing the effect of the Instagram brand context on followers interactions of the Manolo Blahnik and Loewe brands.

sig. $0.959>0.05$. Also, the differences between the average likes of the followers of the Loewe brand and the different categories of brand content are not significant, with an $F$ of 1.268 and a sig. $0.959>0.05$.

On the other hand, in the Manolo Blahnik brand, the range of reactions received a minimum of 4461 and a maximum of 50084 in the case of industrial publications, with the range being very wide, this range increased considerably if the publications were social responsibility publications, going from 5,437 to 89,104 likes, and even greater if they showed commercial content, moving from a range of 3,897 minimum likes and 139,984 maximum likes, with the latter figure being overwhelming.

Meanwhile, in the Loewe brand, the range of reactions had a minimum of 2,414 and a maximum of 407,548 in the case of industrial publications, with this range being extremely wide, although this range increased considerably if they were social responsibility publications, from 2,854 to 123,466 likes. Lastly, if they included commercial content, we moved to a range of

Table 2. Descriptive statistics of the sentiments "likes" generated as a function of brand content.

\begin{tabular}{|c|c|c|c|c|c|c|c|c|}
\hline Brands & & & $N$ & $M$ & $S D$ & $S E$ & Min. & Max. \\
\hline \multirow[t]{5}{*}{ Manolo Blahnik } & Likes & Industrial & 5 & 21632.40 & 18509.533 & 8277.715 & 4461 & 50084 \\
\hline & & Social Responsability & 21 & 22955.90 & 19704.289 & 4299.828 & 5437 & 89104 \\
\hline & & Commercial & 34 & 26229.94 & 28551.822 & 4896.597 & 3897 & 139984 \\
\hline & & Influencers & 1 & 24542.00 & & & 24542 & 24542 \\
\hline & & Total & 61 & 24698.30 & 24572.324 & 3146.164 & 3897 & 139984 \\
\hline \multirow[t]{5}{*}{ Loewe } & Likes & Industrial & 20 & 27539.85 & 89730.057 & 20064.251 & 2414 & 407548 \\
\hline & & Social Responsability & 38 & 14652.58 & 21406.253 & 3472.553 & 2854 & 123466 \\
\hline & & Commercial & 42 & 6276.60 & 3311.325 & 510.949 & 297 & 15559 \\
\hline & & Influencers & 9 & 16385.56 & 15284.727 & 5094.909 & 5446 & 49644 \\
\hline & & Total & 109 & 13932.86 & 40653.225 & 3893.873 & 297 & 407548 \\
\hline
\end{tabular}

Table 3. ANOVA statistic of sentiments "likes" as a function of brand content.

\begin{tabular}{|c|c|c|c|c|c|c|c|}
\hline Brands & & & Sum of squares & gl & Root mean square & $F$ & $p$ \\
\hline \multirow[t]{3}{*}{ Manolo Blahnik } & Likes & Between groups & 190539347.797 & 3 & 63513115.932 & 0.100 & 0.959 \\
\hline & & Within groups & 36037407966.892 & 57 & 632235227.489 & & \\
\hline & & Total & 36227947314.689 & 60 & & & \\
\hline \multirow[t]{3}{*}{ Loewe } & Likes & Between groups & 6238801184.781 & 3 & 2079600394.927 & 1.268 & 0.289 \\
\hline & & Within groups & 172251145770.154 & 105 & 1640487102.573 & & \\
\hline & & Total & 178489946954.936 & 108 & & & \\
\hline
\end{tabular}


297 minimum likes and 15,559 maximum likes, and in influencer publications, this was 5,446 minimum likes and 49,644 maximum likes.

Therefore, $\mathrm{H} 1$ is partially rejected, as brand content does not influence the average number of likes or followers, but it does influence the range of likes depending on the type of content.

Therefore, brand content does not influence the average sentiment generated in the form of likes by followers, but it does influence the reach of those likes. The average number of likes is very high in any of the types of brand content considered, so the sentiment generated by the brand was very positive in any case. This behavior was found in both Manolo Blahnik and Loewe, who achieved a high reach with their industrial brand content, and it substantially improved when the brand content dealt with social responsibility. However, the reach was very notable when it was commercial and influencer content, which may be because this is a luxury brand whose products are very expensive.

Another aspect that could be studied in followers of a brand on Instagram is their comments, since they perform word of mouth of the brand through this social network, thus becoming recommenders, especially when these comments are positive. Therefore, we hypothesise $\mathrm{H} 2, \mathrm{H} 3$, and $\mathrm{H} 4$ for their analysis:

\section{$\mathrm{H} 2$ : Brand content influences positive comments.}

Table 4 shows that followers of the Manolo Blahnik brand reacted with 82 positive comments to industrial publications, with an average of 84.57 positive comments for social responsibility publications and 91.62 positive comments on average for commercial publications, and 121 positive comments for influencers.

Meanwhile, followers of the Loewe brand reacted to industrial publications with 17.65 average of positive comments, with an average of 54.74 positive comments for social responsibility publications, with 22.64 positive comments on average for commercial publications, and 49.56 positive comments for influencers.

Again, for all brand content typologies, the standard deviation was very high, which is expected when studying behaviors on Instagram, because the type of reactions materialized in positive comments by followers is very diverse.

Table 5 shows that according to the $F$ statistic of the ANOVA analysis for a $95 \%$ level of confidence, the differences between the average positive comments of the followers of the Manolo Blahnik brand and the different categories of brand content were not significant, with an $F$ of 0.109 and a sig. $0.954>0.05$. However, the differences between the average positive comments of the followers of Loewe and the different categories of brand content were significant, with an $F$ of 7.292 and a sig. $0.000<0.05$.

On the other hand, in the Manolo Blahnik brand, the range of positive comments had a minimum of 25 and a maximum of 144 in the case of industrial publications, with this range being extensive. This range increased if they were social responsibility publications, from 25 to 258 positive comments, and even more if they were about commercial content, with a broad range from 14 to 340 maximum likes.

Table 4. Descriptive statistics of the positive comments generated according to brand content.

\begin{tabular}{|c|c|c|c|c|c|c|c|c|}
\hline Brands & & & $N$ & $M$ & $S D$ & $S E$ & Min. & Max. \\
\hline \multirow[t]{5}{*}{ Manolo Blahnik } & Positive Comments & Industrial & 5 & 82.00 & 55.027 & 24.609 & 25 & 144 \\
\hline & & Social Responsibility & 21 & 84.57 & 54.579 & 11.910 & 25 & 258 \\
\hline & & Commercial & 34 & 91.62 & 88.961 & 15.257 & 14 & 340 \\
\hline & & Influencers & 1 & 121.00 & & & 121 & 121 \\
\hline & & Total & 61 & 88.89 & 74.696 & 9.564 & 14 & 340 \\
\hline \multirow[t]{5}{*}{ Loewe } & Positive Comments & Industrial & 20 & 17.65 & 13.531 & 3.026 & 4 & 57 \\
\hline & & Social Responsibility & 38 & 54.74 & 52.705 & 8.550 & 8 & 253 \\
\hline & & Commercial & 42 & 22.64 & 14.632 & 2.258 & 5 & 59 \\
\hline & & Influencers & 9 & 49.56 & 55.709 & 18.570 & 18 & 195 \\
\hline & & Total & 109 & 35.14 & 39.558 & 3.789 & 4 & 253 \\
\hline
\end{tabular}

Table 5. ANOVA statistic of positive comments as a function of brand content.

\begin{tabular}{|c|c|c|c|c|c|c|c|}
\hline Brands & & & Sum of squares & gl & Root mean square & $F$ & $p$ \\
\hline \multirow[t]{3}{*}{ Manolo Blahnik } & Positive Comments & Between groups & 1913.024 & 3 & 637.675 & 0.109 & 0.954 \\
\hline & & Within groups & 332853.172 & 57 & 5839.529 & & \\
\hline & & Total & 334766.197 & 60 & & & \\
\hline \multirow[t]{3}{*}{ Loewe } & Positive Comments & Between groups & 29141.152 & 3 & 9713.717 & 7.292 & 0.000 \\
\hline & & Within groups & 139861.784 & 105 & 1332.017 & & \\
\hline & & Total & 169002.936 & 108 & & & \\
\hline
\end{tabular}


In the Loewe brand, the range of positive comments ranged from 4 to 57 in the case of industrial publications, with this being a wide range. This range increased considerably if they were publications of social responsibility, from 8 to 253 positive comments, and if they were of commercial content, from 5 to 59 likes. Lastly, if the publications were about influencers, positive comments ranged from 18 to 195 likes.

Therefore, in the Manolo Blahnik brand, $\mathrm{H} 2$ is partially rejected, as the brand content did not influence the average number of positive comments from followers, although it did influence the maximum number of positive comments reached depending on the type of content. However, in the Loewe brand, $\mathrm{H} 2$ was confirmed, as the brand content influenced the average number of positive comments from followers and influenced the maximum number of positive comments achieved depending on the type of content.

So, the behavior of the follower comments in the two brands analyzed was different. In Manolo Blahnik, the type of brand content did not influence the average comments generated by followers, but it did influence their reach. The average number of positive comments was very considerable in any of the types of brand content considered, so the reputation generated by the brand was very positive in any case. Manolo Blahnik achieved a high reach with its industrial brand content typologies, which substantially improved when the brand content deals with social responsibility. However, its positive comments were even more remarkable when the brand content was commercial. This shows that current and poten- tial consumers of the brand are susceptible to commercial publications, given that it is a luxury product. In Loewe, the positive comments did show significant differences depending on the type of brand content. Social responsibility brand content was the most effective, followed by influencer, commercial, and industrial brand content:

H3: Brand content influences neutral comments.

In Table 6, for the Manolo Blahnik brand, we can observe that industrial brand content generated only 3.20 neutral comments, while the social responsibility brand content had a similar reaction to commercial brand content, as in both cases, it generated a reaction of just over 11 neutral comments, and in the influencers brand content, only four neutral comments.

Meanwhile, for Loewe, it can be observed that industrial brand content generated on average only 1.45 neutral comments, while social responsibility brand content generated 7 neutral comments, commercial brand content 4.1, and the case of influencers generated a reaction of 11.56 neutral comments, generating the most comments.

The ANOVA analysis (see Table 7) for a 95\% level of confidence, of the Manolo Blahnik brand, shows an $F$ of 0.79 and a sig. $0.505<0.05$. Therefore, there were no significant differences in the followers' reactions regarding average neutral comments depending on brand content. Therefore, $\mathrm{H} 3$ is rejected. This may be because the average neutral comment reaction was similar between commercial and social responsibility contents.

Table 6. Descriptive statistics of neutral comments generated based on brand content.

\begin{tabular}{|c|c|c|c|c|c|c|c|c|}
\hline Brands & & & $N$ & $M$ & $S D$ & $S E$ & Min. & Max. \\
\hline \multirow[t]{5}{*}{ Manolo Blahnik } & Neutral Comments & Industrial & 5 & 3.20 & 2.490 & 1.114 & 0 & 5 \\
\hline & & Social Responsibility & 21 & 11.33 & 15.885 & 3.466 & 0 & 71 \\
\hline & & Commercial & 34 & 11.41 & 10.115 & 1.735 & 1 & 41 \\
\hline & & Influencers & 1 & 4.00 & & & 4 & 4 \\
\hline & & Total & 61 & 10.59 & 12.110 & 1.550 & 0 & 71 \\
\hline \multirow[t]{5}{*}{ Loewe } & Neutral Comments & Industrial & 20 & 1.45 & 1.849 & 0.413 & 0 & 6 \\
\hline & & Social Responsibility & 38 & 7.03 & 6.541 & 1.061 & 0 & 27 \\
\hline & & Commercial & 42 & 4.10 & 4.460 & 0.688 & 0 & 19 \\
\hline & & Influencers & 9 & 11.56 & 11.897 & 3.966 & 2 & 40 \\
\hline & & Total & 109 & 5.25 & 6.396 & 0.613 & 0 & 40 \\
\hline
\end{tabular}

Table 7. ANOVA statistic of the neutral comments as a function of brand content.

\begin{tabular}{|c|c|c|c|c|c|c|c|}
\hline Brands & & & Sum of squares & gl & Root mean square & $F$ & $p$ \\
\hline \multirow[t]{3}{*}{ Manolo Blahnik } & Neutral Comments & Between groups & 351.052 & 3 & 117.017 & 0.790 & 0.505 \\
\hline & & Within groups & 8447.702 & 57 & 148.205 & & \\
\hline & & Total & 8798.754 & 60 & & & \\
\hline \multirow[t]{3}{*}{ Loewe } & Neutral Comments & Between groups & 822.547 & 3 & 274.182 & 8.006 & 0.000 \\
\hline & & Within groups & 3595.765 & 105 & 34.245 & & \\
\hline & & Total & 4418.312 & 108 & & & \\
\hline
\end{tabular}


However, in the Loewe brand, the ANOVA showed an $F$ of 8.006 and a sig. $0.000<0.05$. Therefore, there were significant differences in the followers' reactions regarding average neutral comments depending on brand content. Therefore, $\mathrm{H} 3$ is confirmed, with influencer publications generating the most neutral comments, followed by social responsibility publications.

As for the neutral comments generated by the different types of brand content among followers, the results showed that the average neutral comments were similar between commercial and social responsibility contents and scarce in industrial content for Manolo Blahnik. For Loewe, there were significant differences, with more neutral comments generated by influencer publications, followed by social responsibility, commercial, and industrial content:

$\mathrm{H} 4$ : Brand content influences negative comments.

Table 8 shows how the negative comments from followers were not substantial in any of the cases. Specifically, in the Manolo Blahnik brand on average, 0.8 in industrial brand content, 2.62 in social responsibility brand content, 1.83 in commercial, and 5 in influencers. With null minimums in most cases and maximums of 2 for industrial, 27 in social responsibility, and 19 in commercial contents.

Meanwhile, there was an average of 0.55 in industrial brand content for the Loewe brand, 0.87 in social responsibility brand content, 1.1 in commercial content, and 2.56 in influencers content. With null minimums in all cases and maximums of 2 for industrial, 5 for social responsibility, 4 for commercial, and 13 for influencers content.

Concerning the ANOVA analysis (Table 9) for a 95\% confidence level, for the Manolo Blahnik brand, it can be observed that there were no significant differences in the negative comments average about the type of brand content disseminated by the firm, so $\mathrm{H} 4$ is rejected. However, for the Loewe brand, it can be affirmed that there were significant differences in the average of negative comments about the type of brand content disseminated by the company, so $\mathrm{H} 4$ is confirmed.

In general terms, industrial, social responsibility, and commercial brand content publications did not generate negative comments in either firm or the influencer brand content type, with these results being very favorable for the brands' reputation.

\section{Discussion and Conclusions}

According to Castillo-Abdul et al. (2020), branded content as a communication and marketing strategy allows positioning fashion brands and promoting interactions with their audiences. In this sense, this research concludes that branded content does not influence the average number of sentiments generated in the interactions represented by likes in the samples studied. However, it did impact their scope, with this finding considered as a contribution to the theoretical implications of this study.

On the one hand, the study showed a high average number of likes in all types of branded content considered, implying a very positive brand sentiment in every case. This behavior was observed in both the Manolo

Table 8. Descriptive statistics of the negative comments generated according to brand content.

\begin{tabular}{|c|c|c|c|c|c|c|c|c|}
\hline Brands & & & $N$ & $M$ & $S D$ & $S E$ & Min. & Max. \\
\hline \multirow[t]{5}{*}{ Manolo Blahnik } & Negative Comments & Industrial & 5 & 0.80 & 0.837 & 0.374 & 0 & 2 \\
\hline & & Social Responsibility & 21 & 2.62 & 5.775 & 1.260 & 0 & 27 \\
\hline & & Commercial & 34 & 1.74 & 3.440 & 0.590 & 0 & 19 \\
\hline & & Influencers & 1 & 5.00 & & & 5 & 5 \\
\hline & & Total & 61 & 2.02 & 4.256 & 0.545 & 0 & 27 \\
\hline \multirow[t]{5}{*}{ Loewe } & Negative Comments & Industrial & 20 & 0.55 & 0.826 & 0.185 & 0 & 2 \\
\hline & & Social Responsibility & 38 & 0.87 & 1.234 & 0.200 & 0 & 5 \\
\hline & & Commercial & 42 & 1.10 & 1.206 & 0.186 & 0 & 4 \\
\hline & & Influencers & 9 & 2.56 & 4.246 & 1.415 & 0 & 13 \\
\hline & & Total & 109 & 1.04 & 1.666 & 0.160 & 0 & 13 \\
\hline
\end{tabular}

Table 9. ANOVA statistic of negative comments as a function of brand content.

\begin{tabular}{|c|c|c|c|c|c|c|c|}
\hline Brands & & & Sum of squares & gl & Root mean square & $\mathrm{F}$ & Sig. \\
\hline \multirow[t]{3}{*}{ Manolo Blahnik } & Negative Comments & Between groups & 26.614 & 3 & 8.871 & 0.477 & 0.700 \\
\hline & & Within groups & 1060.370 & 57 & 18.603 & & \\
\hline & & Total & 1086.984 & 60 & & & \\
\hline \multirow[t]{3}{*}{ Loewe } & Negative Comments & Between groups & 26.720 & 3 & 8.907 & 3.424 & 0.020 \\
\hline & & Within groups & 273.133 & 105 & 2.601 & & \\
\hline & & Total & 299.853 & 108 & & & \\
\hline
\end{tabular}


Blahnik and Loewe brands, which achieved a high reach for their industrial content, and even improved substantially when the publication dealt with social responsibility. It should be considered that this empathy towards social responsibility content is framed within the Covid-19 pandemic, which undoubtedly affected consumers' interests and the way they acted on specific content. This study allows us to recognize the diversity of reactions and comments of the same strategy by two luxury fashion brands. In this sense, the characteristics of each audience profile should be considered when communicating content.

The comments analyzed in both brands were different. In the case of Manolo Blahnik, the type of brand content did not influence the average number of comments generated by followers, but it did influence their reach. The average number of positive comments was very considerable for any of the content types considered. According to this point of view, branded content generates engagement with users, determining a relationship based on interaction, as demonstrated in previous literature (Dessart, 2017). Manolo Blahnik achieved a large reach with its industrial brand content typologies, which substantially improved when the content dealt with social responsibility, but the reach of its positive comments was even more remarkable when it was commercial. This denotes that the brand's current and potential consumers are susceptible to commercial posts, which are often eye-catching, leading them to purchases. At Loewe, positive comments did show significant differences according to the type of brand content. Social responsibility content seemed to be the most effective, followed by the influencer, commercial, and industrial ones. This brand strengthened its links with society through initiatives related to the pandemic and reinforced its social responsibility content, which positively impacted its image and reputation.

Regarding the comments generated by the different types of brand content among followers, in the case of Manolo Blahnik, the results showed that the average number of neutral comments was similar between commercial and social responsibility content and low in industrial content. In the case of Loewe, there were significant differences, with more neutral comments generated by influencers' publications, followed by social responsibility, commercial and industrial content. In general terms, in both companies, the publications of industrial, social responsibility, commercial, and influencer content did not generate negative comments, which allows us to establish with certainty that the use of these contents achieved the main objective of the brands, to connect positively with the public.

Among the limitations of the study, it is worth noting the importance of the analysis of the values, considering that when counting the reaction frequencies, if these exceeded a thousand, the figures observed were only approximate to a hundred, so that the exact data in these cases could be affected.
On the other hand, conventionally, sentiment analysis considers positive, negative, and neutral dimensions in the classification of texts. However, in sentiment analysis, some pictograms used in social network communication were difficult to classify simply as positive or negative, as they could be reductionist or simplifying. The accuracy of the lexicon-supported approach is drastically diminished in the presence of emoticons and abbreviated texts, as they are not part of the predefined sentiment lexicon

This research confirms that content categorization into industrial, commercial, social responsibility, or influencer is helpful for brands and advertising agencies and even more so when establishing future communication and marketing actions. However, in future research, outside the pandemic framework, it will be necessary to observe whether socially responsible content surpasses the positive reactions to commercial content or not.

The implications of the study reach both theory and practice of luxury fashion marketing in social media. In theory, the study presents a new perspective on the dynamics of content creation in social media and exhibits the application of a methodology for analysis, thereby facilitating the understanding of the meanings of images for the consumer. In terms of practice and management, it offers new knowledge about communication and marketing in social networks, especially related to interaction with the brand and its products.

This work offers advances in the theory and practice of advertising effectiveness of brands, particularly luxury brands, by decoding consumer engagement with the brand. The fashion industry should continue to support branded content publishing on social networks such as Instagram, which favor interactions with audiences and the sales funnel, and the dissemination of new formats that attract and generate engagement with users. It should be noted that the Instagram network itself is facilitating these new formats over time; we have moved from photos to stories, IGTV, and the most recent, reels.

Finally, it is essential to establish this study as a reference framework for future longitudinal research studies to learn about the progress and changes in consumer behavior and interactions generated in this type of branded content, with the suggestion of incorporating new tools into networks such as Instagram. Similarly, among the future lines of research, it is necessary to discover the implications between the use of this type of strategy and the impact it causes on the reputation of fashion brands.

\section{Conflict of Interests}

The authors declare no conflict of interests.

\section{References}

Ashley, C., \& Tuten, T. (2015). Creative strategies in social media marketing: An exploratory study of branded 
social content and consumer engagement. Psychology \& Marketing, 32(1), 15-27. https://doi.org/ 10.1002/mar.20761

Barger, V. A., \& Labrecque, L. (2013). An integrated marketing communications perspective on social media metrics. International Journal of Integrated Marketing Communications, Spring 2013, 64-76. https:// ssrn.com/abstract $=2280132$

Belanche, D., Casaló, L. V., Flavián, M., \& IbáñezSánchez, S. (2021). Understanding influencer marketing: The role of congruence between influencers, products, and consumers. Journal of Business Research, 132, 186-195. https://doi.org/0.1016/ j.jbusres.2021.03.067

Bentley, K., Chu, C., Nistor, C., Pehlivan, E., \& Yalcin, T. (2021). Social media engagement for global influencers. Journal of Global Marketing, 34(3), 205-219. https://doi.org/10.1080/08911762.2021.1895403

Bezbaruah, S., \& Trivedi, J. (2020). Branded content: A bridge building Gen Z's consumer-brand relationship. Vision, 24(3), 300-309. https://doi.org/ 10.1177/0972262920930167

Bonilla, M., del Olmo-Arriaga, J., \& Andreu, A. (2019). The interaction of Instagram followers in the fast fashion sector: The case of Hennes and Mauritz (H\&M). Journal of Global Fashion Marketing, 10(4), 342-357. https://doi.org/10.1080/20932685.2019.1649168

Bug, P., \& Blau, L. (2020). Fashion product placement in international tv series. In P. Bug (Ed.), Fashion and film (pp. 59-80). Springer. https://doi.org/10.1007/ 978-981-13-9542-0_4

Calder, B. J., Isaac, M. S., \& Malthouse, E. C. (2016). How to capture consumer experiences: A context-specific approach to measuring engagement predicting consumer behavior across qualitatively different experiences. Journal of Advertising Research, 56(1), 39-52. https://doi.org/10.2501/JAR-2015-028

Cantista, I., \& Sádaba, T. (2020). Understanding luxury fashion: Origins and contemporary issues. In I. Cantista \& T. Sádaba (Eds.), Understanding luxury fashion (pp. 3-12). Palgrave Macmillan.

Capriotti, P. (2013). Planificación estratégica de la imagen corporativa [Strategic corporate image planning]. IIRP Instituto de Investigación en Relaciones Públicas. https://bit.ly/2zSzDI2

Casaló, L., Flavián, C., \& Ibañez-Sánchez, S. (2017). Understanding consumer interaction on Instagram: The role of satisfaction, hedonism, and content characteristics cyberpsychology. Behavior and Social Networking, 6(20), 369-375. https://doi.org/10.1089/cyber. 2016.0360

Casaló, L., Flavián, C., \& Ibáñez-Sánchez, S. (2020). Be creative, my friend! Engaging users on Instagram by promoting positive emotions. Journal of Business Research, 130, 416-425. https://doi.org/10.1016/ j.jbusres.2020.02.014

Castañeda, J. A., Frías-Jamilena, D. M., RodríguezMolina, M. A., \& Jones, A. (2020). Online mar- keting effectiveness-The influence of information load and digital literacy, a cross-country comparison. Electronic Markets, 30, 759-773. https://doi.org/ 10.1007/s12525-019-00372-9

Castillo-Abdul, B., Bonilla-del-Río, M., \& NúñezBarriopedro, E. (2021). Influence and relationship between branded content and the social media consumer interactions of the luxury fashion brand Manolo Blahnik. Publications, 9(1), 1-14. https:// doi.org/10.3390/publications9010010

Castillo-Abdul, B., Pérez-Escoda, A., \& Civila, S. (2021). Social media fostering happiness management: Three luxury brands case study on Instagram. Corporate Governance. Advance online publication. https://doi.org/10.1108/CG-05-2021-0201

Castillo-Abdul, B., Romero-Rodríguez, L. M., \& PérezRodríguez, A. (2020). Branded content in fashion research: Bibliometric analysis by correlations. Academy of Marketing Studies Journal, 24(1). https:// www.abacademies.org/articles/branded-contentin-fashion-research-bibliometric-analysis-bycorrelations-8990.html

Chen, L., \& Shupei, Y. (2019). Influencer marketing: How message value and credibility affect consumer trust of branded content on social media. Journal of Interactive Advertising, 19(1), 58-73. https://doi.org/ 10.1080/15252019.2018.1533501

Choi, W., \& Lee, Y. (2019). Effects of fashion vlogger attributes on product attitude and content sharing. Fashion and Textile, 6(6), 1-18. https://doi.org/ 10.1186/s40691-018-0161-1

Correia-Loureiro, S., Maximiano, M., \& Panchapakesan, P. (2018). Engaging fashion consumers in social media: The case of luxury brands. International Journal of Fashion Design, Technology and Education, 11(3), 310-321. https://doi.org/10.1080/17543266. 2018.1431810

Cuesta-Valiño, P., Gutiérrez-Rodríguez, P., \& NúñezBarriopedro, E. (2021). The role of consumer happiness in brand loyalty: A model of the satisfaction and brand image in fashion. Corporate Governance: The International Journal of Business in Society. Advance online publication. https://doi.org/10.1108/CG-032021-0099

Dessart, L. (2017). Social media engagement: A model of antecedents and relational outcomes. Journal of Marketing Management, 33(5), 375-399. https:// doi.org/10.1080/0267257X.2017.1302975

González-Romo, Z. F., \& Plaza-Romero, N. (2015). Digital marketing strategies in the luxury fashion sector. Interaction and social networks as a necessary tool. Hipertext.Net, 15, 17-27. https://raco.cat/ index.php/Hipertext/article/view/326495

Hair, J. F., Bush, R. P., \& Ortinau, D. J. (2010). Investigación de mercados en un ambiente de información digital [Market research in a digital information environment]. McGraw Hill.

Jin, S. V., \& Ryu, E. (2020). Instagram fashionistas, luxury 
visual image strategies and vanity. Journal of Product \& Brand Management, 29(3), 355-368. https:// doi.org/10.1108/JPBM-08-2018-1987

Kemp, S. (2021). Digital 2021: Global digital overview. We Are Social; Hootsuite. https://datareportal.com/ reports/digital-2021-global-overview-report

Kim, K., \& Kim, E. (2020). Fashion marketing trends in social media and sustainability in fashion management. Journal of Business Research, 117, 508-509. https://doi.org/10.1016/j.jbusres.2020.06.001

Kong, H. M., Witmaier, A., \& Ko, E. (2021). Sustainability and social media communication: How consumers respond to marketing efforts of luxury and non-luxury fashion brands. Journal of Business Research, 131, 640-651. https://doi.org/10.1016/ j.jbusres.2020.08.021

Núñez-Barriopedro, E., Cuesta-Valiño, P., \& Rodríguez, P. G. (2013). Posicionamiento del valor de marca de firmas de moda [Brand equity positioning of fashion firms]. aDResearch: Revista Internacional de Investigación en Comunicación, 7, 8-19.

Otzen, T., \& Manterola, C. (2017). Técnicas de muestreo sobre una población a estudio [Sampling techniques on a population study]. International Journal of Morphology, 35(1), 227-232. https://scielo.conicyt.cl/ pdf/ijmorphol/v35n1/art37.pdf

Pérez-Curiel, C., \& Sanz-Marcos, P. (2019). Branding, influencers and new targets in the communication of fashion and luxury. Prisma Social, 24, 1-24. https:// revistaprismasocial.es/article/view/2826

Pérez-Escoda, A., Delgado, A., \& Renés-Arellano, P. (2016). Mobile apps and social media: Enablers of media literacy in primary school students. In J. M. Dodero, M. S. I. Sáiz, \& I. R. Rube (Eds.), Proceedings of the 5th international conference on technological ecosystems for enhancing multiculturality (Article 28). ACM. https://doi.org/10.1145/3144826. 3145418

Pérez-Escoda, A., Pedrero-Esteban, L. M., Rubio-Romero, J., \& Jiménez-Narros, C. (2021). Fake news reaching young people on social networks: Distrust challenging media literacy. Publications, 9(2), 1-16. https:// doi.org/10.3390/publications9020024

Pérez-Tornero, J. M., \& Pedrero-Esteban, L. M. (2020). Las coordenadas digitales del ecosistema comunicativo [The digital coordinates of the communication ecosystem]. In L. M. Pedrero-Esteban \& A. PérezEscoda (Eds.), Cartografía de la comunicación postdigital: Medios y audiencias en la Sociedad de la COVID-19 [Postdigital communication cartography: Media and audiences in Covid-19 society] (pp. 37-56). Civitas Thomson Reuters.

Pinto, M. B., \& Yagnik, A. (2017). Fit for life: A content analysis of fitness tracker brands use of Facebook in social media marketing. Journal of Brand Management, 24, 49-67. https://doi.org/10.1057/ s41262-016-0014-4

Sádaba, C., \& Pérez-Escoda, A. (2020). La generación streaming y el nuevo paradigma de la comunicación digital [The streaming generation and the new paradigm of digital communication]. In L. M. Pedrero-Esteban \& A. Pérez-Escoda (Eds.), Postdigital communication cartography: Media and audiences in Covid-19 society (pp. 97-114). Civitas Thomson Reuters.

Sánchez-Cobarro, P., Molina-Castillo, F., \& AlcázarCáceres, C. (2021). The brand-generated content interaction of Instagram stories and publications: A comparison between retailers and manufacturers. Journal of Theoretical Applied Electronic Commerce Research, 16(3), 513-524. https://doi.org/10.3390/ jtaer16030031

Voorveld, H. A. M. (2019). Brand communication in social media: A research agenda. Journal of Advertising, 48(1), 14-26. https://doi.org/10.1080/ 00913367.2019 .1588808

Voorveld, H. A. M., Van Noort, G., Muntinga, D. G., \& Bronner, F. (2018). Engagement with social media and social media advertising: The differentiating role of platform type. Journal of Advertising, 47, 38-54. https://doi.org/10.1080/00913367.2017.1405754

Wahid, R., \& Gunarto, M. (2021). Factors driving social media engagement on Instagram: Evidence from an emerging market. Journal of Global Marketing. Advance online publication. https://doi.org/ 10.1080/08911762.2021.1956665

Wu, C., Guaita-Martínez, J., \& Martín-Martín, J. (2020). An analysis of social media marketing strategy and performance in the context of fashion brands: The case of Taiwan. Psychology Marketing, 37(9), 1185-1193. https://doi.org/10.1002/mar.21350

\section{About the Authors}

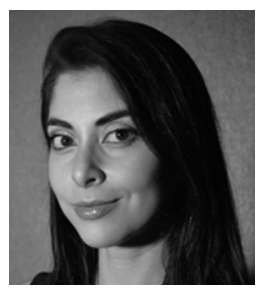

Bárbara Castillo-Abdul is a predoctoral researcher at the Department of Communication Sciences and Sociology of the Rey Juan Carlos University (Spain) and a visiting professor at ESAI Business School, Espiritu Santo University in Ecuador. Student of the PhD program in communication at the University of Huelva. She is a member of European Communication Research and Education Association, International Association for Media and Communication Research, and Euro-American Interuniversity Network of Research on Media Competences for Citizenship. https://orcid.org/0000-0002-3711-1519 


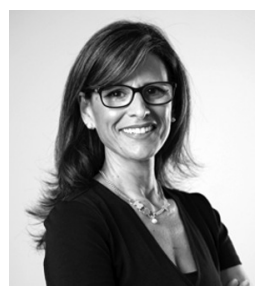

Ana Pérez-Escoda (PhD, University of Salamanca) is an assistant professor in University of Antonio de Nebrija, Madrid (Spain). She is member of the research group Nebrija Innomedia and she is currently member of the European Project Horizon 2020 Mediatized.EU. She has participated in different national and international research projects, and she has authored several impact articles and books in the field of social media, digital communication, digital literacy, innovation in education, media literacy, and digital skills. https://orcid.org/0000-0002-4895-0043

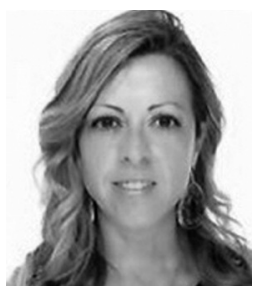

Estela Núñez-Barriopedro holds a PhD from University of Alcalá (UAH). She is a lecturer and researcher at UAH. She also worked for University Carlos III of Madrid and International University of La Rioja. She has received several awards in teaching and research. She is member of the International Association on Public and Non-Profit Marketing and member of Spanish Association of Academic and Professional Marketing. Her research interests include international marketing, branding, social marketing, economics of happiness, and creativity. https://orcid.org/0000-0002-2292-8147 